A Structured Programming Approach to Data 
Macmillan Computer Science Series

Consulting Editor:

Professor F. H. Sumner, University of Manchester

J. K. Buckle, The ICL 2900 Series

Andrew J. T. Colin, Programming and Problem-solving in Algol 68

S. M. Deen, Fundamentals of Data Base Systems

David Hopkin and Barbara Moss, Automata

A. Learner and A. J. Powell, An Introduction to Algol 68 through Problems

A. M. Lister, Fundamentals of Operating Systems

Brian Meek, Fortran, PL/I and the Algols

I. R. Wilson and A. M. Addyman, A Practical Introduction to Pascal 


\section{A Structured \\ Programming \\ Approach to Data}

\section{Derek Coleman}

Department of Computation, LIMIST

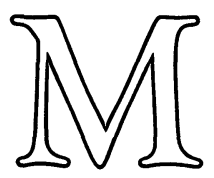


(C) Derek Coleman 1978

All rights reserved. No part of this publication may be reproduced or transmitted, in any form or by any means, without permission.

First published 1978 by

THE MACMILLAN PRESS LTD

London and Basingstoke

Associated companies in Delhi Dublin

Hong Kong Johannesburg Lagos Melbourne

New York Singapore and Tokyo

British Library Cataloguing in Publication Data

Coleman, Derek

A structured programming approach to data.

- (Macmillan computer science series).

1. Structured programming

I. Title

001.6 Q QA76.6

ISBN 978-0-333-21943-0

ISBN 978-1-349-15981-9 (eBook)

DOI 10.1007/978-1-349-15981-9

This book is sold subject to the standard conditions of the Net Book Agreement.

The paperback edition of this book is sold subject to the condition that it shall not, by way of trade or otherwise, be lent, resold, hired out, or otherwise circulated without the publisher's prior consent in any form of binding or cover other than that in which it is published and without a similar condition including this condition being imposed on the subsequent purchaser. 


\section{Contents}

Preface $\quad$ ix

Acknowledgements $\quad$ xi

1. An Overview of Program Design 1

1.1 Introduction - The Software Crisis 1

1.2 Objectives of Program Design 2

1.3 The Heart of the Problem 3

$\begin{array}{ll}1.4 \text { Stepwise Refinement } & 4\end{array}$

1.5 What Do We Mean When We Say a Program 'Works'? 4

$\begin{array}{ll}1.6 \text { Summary } & 5\end{array}$

1.7 Bibliographical Notes 5

2. Program Design Notation 6

2.1 An Abstract Programming Language 6

2.2 Structuring Control $\quad 6$

$\begin{array}{lr}2.3 \text { Structuring Data } & 15\end{array}$

2.4 What is a Data Structure? 16

$\begin{array}{ll}2.5 \text { Unstructured Data Types } & 17\end{array}$

2.6 Implementation of Unstructured Types 19

$\begin{array}{ll}2.7 \text { Summary } & 19\end{array}$

2.8 Bibliographical Notes $\quad 20$

3. Arrays 21

$\begin{array}{ll}3.1 \text { Array Structures } & 21\end{array}$

$\begin{array}{ll}3.2 \text { Arrays and Functions } & 22\end{array}$

3.3 Implementation of Arrays $\quad 24$

$\begin{array}{ll}3.4 \text { Summary } & 26\end{array}$

3.5 Bibliographical Notes 26

4. Simple Data Structuring $\quad 27$

$\begin{array}{ll}4.1 \text { Record Types } & 27\end{array}$

4.2 Implementation of Record Types 29 
4.3 Use of Structured Types $\quad 29$

$\begin{array}{ll}4.4 \text { Variant Types } & 31\end{array}$

4.5 Implementation of Variant Types $\quad 34$

$\begin{array}{ll}4.6 \text { Summary } & 34\end{array}$

4.7 Bibliographical Notes $\quad 35$

5. On Program Design 36

5.1 Stepwise Refinement of Programs 36

5.2 Two Examples $\quad 37$

$\begin{array}{ll}5.3 \text { Summary } & 47\end{array}$

5.4 Bibliographical Notes $\quad 48$

$\begin{array}{ll}\text { Exercises 1 } & 49\end{array}$

6. Set Structures 53

6.1 Introduction $\quad 53$

6.2 Set Operations $\quad 54$

6.3 Use of Set Structures $\quad 56$

6.4 Implementation of Set Structures $\quad 59$

$\begin{array}{ll}6.5 \text { Summary } & 64\end{array}$

6.6 Bibliographical Notes $\quad 65$

7. The Class Construct 66

7.1 Using and Implementing Data Structures 66

$\begin{array}{ll}7.2 \text { Classes } & 68\end{array}$

$\begin{array}{ll}7.3 \text { Implementation of Classes } & 71\end{array}$

$\begin{array}{ll}7.4 \text { Summary } & 79\end{array}$

$\begin{array}{ll}7.5 \text { Bibliographical Notes } & 79\end{array}$

8. Dynamic Data Structures $\quad 80$

$\begin{array}{ll}8.1 \text { Introduction } & 80\end{array}$

8.2 Basic Implementation Techniques for Dynamic Data Structures 83

$\begin{array}{ll}\text { 8.3 Linear Linked Lists } & 84\end{array}$

8.4 Storage Management for Dynamic Data Structures 87

8.5 Linear Linked List Implementation of Integersets 88

$\begin{array}{ll}8.6 \text { Summary } & 94\end{array}$

$\begin{array}{ll}8.7 \text { Bibliographical Notes } & 94\end{array}$

9. Sequences $\quad 95$

9.1 Introduction $\quad 95$

9.2 Operations on Sequences 98

$\begin{array}{ll}9.3 \text { Storage Structures for Sequences } & 104\end{array}$

$\begin{array}{ll}9.4 \text { Queues } & 108\end{array}$ 
10. Simple Searching Teciniques 116

10.1 Sparse Mappings 116

10.2 Sparsity and Searching $\quad 117$

$\begin{array}{ll}10.3 \text { Linear Search } & 118\end{array}$

10.4 Merge Search 121

10.5 Binary Search 123

10.6 Properties of Binary Searching $\quad 124$

10.7 Summary 126

$\begin{array}{ll}10.8 \text { Bibliographical Notes } & 127\end{array}$

11. Hashing Techniques 128

11.1 Introduction 128

11.2 Choice of a Hashing Function $\quad 130$

11.3 Collision Handling by Open Addressing 131

11.4 Ordered Hashing 134

11.5 Chained Hashing 138

11.6 Efficiency of Hashing Methods 139

11.7 Summary 140

$\begin{array}{ll}11.8 \text { Bibliographical Notes } & 140\end{array}$

12. Recursion and Recursive Algorithms 141

12.1 Recursion 141

12.2 Mechanics of Recursion 144

12.3 Removal of Recursion 146

12.4 Recursion in the Design of Algorithms $\quad 150$

12.5 Conclusion 156

12.6 Summary 157

$\begin{array}{ll}12.7 \text { Bibliographical Notes } & 157\end{array}$

13. Binary Search Trees 158

13.1 Introduction 158

13.2 Operations on Binary Trees $\quad 162$

13.3 Binary Search Trees 164

13.4 The Shape of Binary Search Trees 171

13.5 Implementation of Binary Trees 173

13.6 Conclusion $\quad 180$

13.7 Summary 180

$\begin{array}{lr}13.8 \text { Bibliographical Notes } & 180\end{array}$ 
$\begin{array}{ll}\text { Exercises } 3 & 181\end{array}$

14. Designing Programs From Data Structures 187

$\begin{array}{ll}14.1 \text { Introduction } & 187\end{array}$

14.2 Traversing Binary Trees 187

14.3 Input of Advanced Data Structures 192

14.4 Program Construction Rules 198

14.5 Systematic Design of File Processing Programs 201

14.6 Conclusion 209

14.7 Summary 209

14.8 Bibliographical Notes 209

$\begin{array}{ll}\text { Exercises } 4 & 210\end{array}$

$\begin{array}{ll}\text { References } & 217\end{array}$

$\begin{array}{ll}\text { Index } & 221\end{array}$ 


\section{Preface}

Much of current programming practice is basically empirical and ad hoc in approach. Each problem is tackled without relation to those that have gone before; experiences are made and stored as a series of fragments. Now, under the pressure of events, this unsatisfactory state of affairs is coming to an end. Programming is becoming a technology, a theory known as structured programming is developing. The purpose of a theory is to categorise and explain existing practice, thus enabling it to be improved through the development of new and sharper techniques. The resulting experiences have then to be fed back into the theory so that the process of enrichment may continue. This dialectical relationship between theory and practice is essential to a healthy programming technology. The lack of such a relationship in the 1950s and 60s and the accompanying software crisis certainly confirm the converse of this proposition.

My aim in writing this book has been to explain the current state of the theory of structured programming, so that it may be used to improve the reader's practice. The book deals with two facets of programming - how to design a program in terms of abstract data structures and how to represent the data structures on real and bounded computers. The separation between program design and data structure representation leads to more reliable and flexible programs. The introduction and use of an abstract programming language as the notation for expressing both program design and the structure of data ensures, as far as is possible, that the description is machine and language independent. The reader can use the notation (or his own personal variant) for the design of structured programs whatever the actual language to be used. The ease of this task depends largely on the suitability of the language for structured programming. Some languages, such as BASIC, are clearly quite inadequate for the task owing to the paucity of their semantics. Other languages such as Pascal and its derivatives, embody in practical and tested form, the theory of structured programming. Of necessity, therefore, I have adopted a Pascal-like notation.

The book constitutes a second-level self-contained text on the role of data structuring in programming and therefore assumes a knowledge of the basic concepts of programming in a high-level language. It has evolved from the second-year undergraduate lecture course on 'Data Structures' that I have given at UMIST over the past six years. It presents as a coherent whole the ideas of Dijkstra, Hoare and Wirth on structured programming together with the earlier 
work of Knuth on data structures. It is hoped that the book will prove useful to all computation and computer science students doing a further course on programming, as well as to the professional programmer in commerce or industry. It is to be emphasised, however, that the ideas discussed in this book are meant to be put into use and tested in the everyday programming activity of the reader. Without interaction with practice they are dead and meaningless.

I have included four sets of exercises covering all the material in the book and have attempted to avoid questions that can be answered by direct quotation from the text. The exercises generally relate to material in more than one chapter and have been grouped accordingly. Life seldom presents us with clear-cut exercises of the form given here; it is therefore to real life that the reader should look for meaningful practice of the concepts discussed in this book. 


\section{Acknowledgements}

I owe a great deal to Professor J. S. Rohl of the University of Western Australia, who first encouraged me to set my ideas down in book form. I would also like to thank Geoff King and the many other UMIST students who have contributed to this book in numerous ways. David Watt, Clive Coleman, Ronan Sleep and John Reynolds all read the draft manuscript and made many helpful comments and suggestions. I have also received much advice and assistance from my colleagues at UMIST, and for this I am extremely grateful. Special thanks go to Mrs I. Betton, Miss M. O'Brien and Mrs B. Sharples, who had the unenviable task of typing the manuscript. Finally I would like to thank Joan, Abra and Robert Coleman for all their support while this book was in preparation.

DEREK COLEMAN 